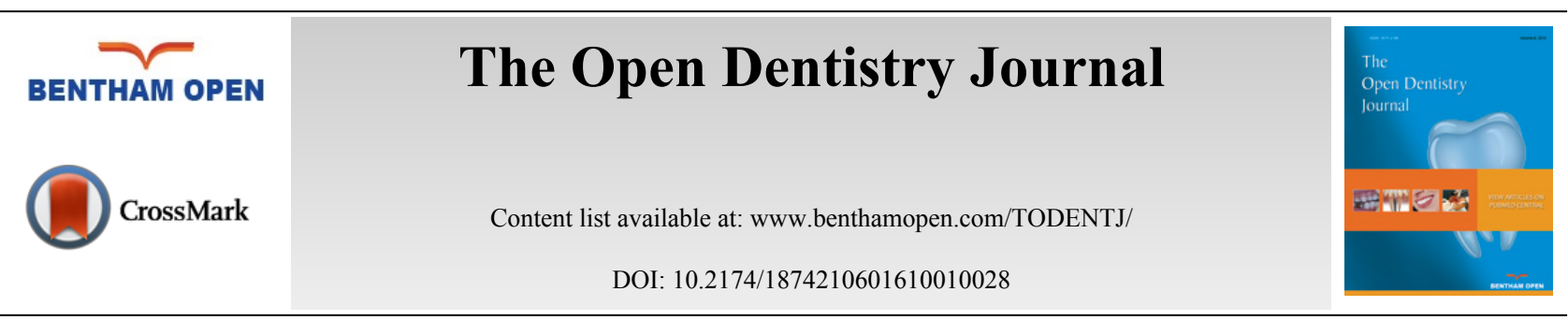

\title{
The Use of the Digital Smile Design Concept as an Auxiliary Tool in Aesthetic Rehabilitation: A Case Report
}

\author{
Piero Rocha Zanardi ${ }^{1, *}$, Raquel Laia Rocha Zanardi², Roberto Chaib Stegun ${ }^{1}$, Newton Sesma ${ }^{1}$, Bru- \\ no Costa $^{1}$ and Dalva Cruz Laganá ${ }^{1}$ \\ ${ }^{1}$ Department of Prosthodontics, School of Dentistry, University of São Paulo, São Paulo, Brazil \\ ${ }^{2}$ Graduated in Dentistry, School of Dentistry, University of São Paulo, São Paulo, Brazil
}

\begin{abstract}
The digital smile design is a practical diagnosis method that can assist the clinician to visualize and measure dentogingival discrepancies. This clinical report aims to present the associated steps, from the diagnosis of the alterations diagnosis through to the final aesthetic result. A 37-years-old female patient presented as her main complaint the tooth form and colour discrepancies. Applying the digital smile design principle, the necessary measures for a harmonic smile correction could be accurately determined. The initial diagnosis led to a wax up of the master cast that was duplicated in acrylic resin directly in the mouth. This temporary restoration guided the periodontal surgery and the final pressed ceramic crown restoration. We conclude that the digital smile design concept seems to be a useful tool to achieve a satisfactory aesthetic result.
\end{abstract}

Keywords: All ceramic crown, Dental aesthetics, Dental porcelain, Digital smile design, Post-Core technique, Pressed ceramic.

\section{INTRODUCTION}

Rehabilitation treatments follow in most cases very similar diagnosis phases to achieve a satisfactory final result [1]. In this way, the development of treatment protocols can clarify any discrepancy identification as well as guide subsequent decisions. Digital smile design seems to be a useful diagnosis tool for dentogingival alterations. With few but correct photographs digital planning presents simple steps to evaluate size, form and tooth position as well as gingival contour [2]. As treatment option to anterior region, the use of fibreglass post associated to a press ceramic crown or all ceramic crown seems to be the most natural treatment option. A Fibreglass post may not influence the final colour of the crown like others metallic posts do [3], leading to increased treatment predictability. Aesthetic treatment may involve a multidisciplinary approach to obtain satisfactory results. So that the prosthetic planning may achieve the expected results some procedures of different areas [4] must be performed. During the digital design, some shape discrepancies can be seen. Particularly in cases of short clinical crowns, an interaction with the periodontist may be necessary to plan the surgical procedures $[5,6]$. In this way, this case report presents the use of digital smile design as a diagnosis tool to establish a multidisciplinary approach for an aesthetic challenge.

\section{CASE REPORT}

A 37-year-old white female, with good general health was referred to the Centre of Excellence in Prostheses and Implants (CEPI) at the School of Dentistry, University of São Paulo, São Paulo, Brazil for treatment. After the patient agreed to and signed the informed consent the diagnosis evaluation was initiated. Her chief complaint was the form and colour discrepancies caused by different treatments performed by different clinicians at different moments. The patient reports that she always received the same answer when she asked about the discrepancies: "This is what can be done since the other crowns won't be changed" (Fig. 1). The opaque appearance of the right lateral and central incisor was

\footnotetext{
* Address correspondence to this author at the Department of Prosthodontics, School of Dentistry, University of São Paulo, Av. Prof Lineu Prestes
} 2227, Cidade Universitária, Postcode 05508-000, São Paulo, SP, Brazil; Tel: +55 11 3091-7885; E-mail: pieroznd@gmail.com.br 
due to the large amount of metal under the ceramic restoration. The initial radiography (Fig. 2) suggested a core-crown that was confirmed during treatment.

The left central incisor presented a feldspathic porcelain veneer with satisfactory translucence. The left lateral incisor also presented a porcelain veneer but it was fractured since the remaining crown structure had many lingual and proximal restorations.

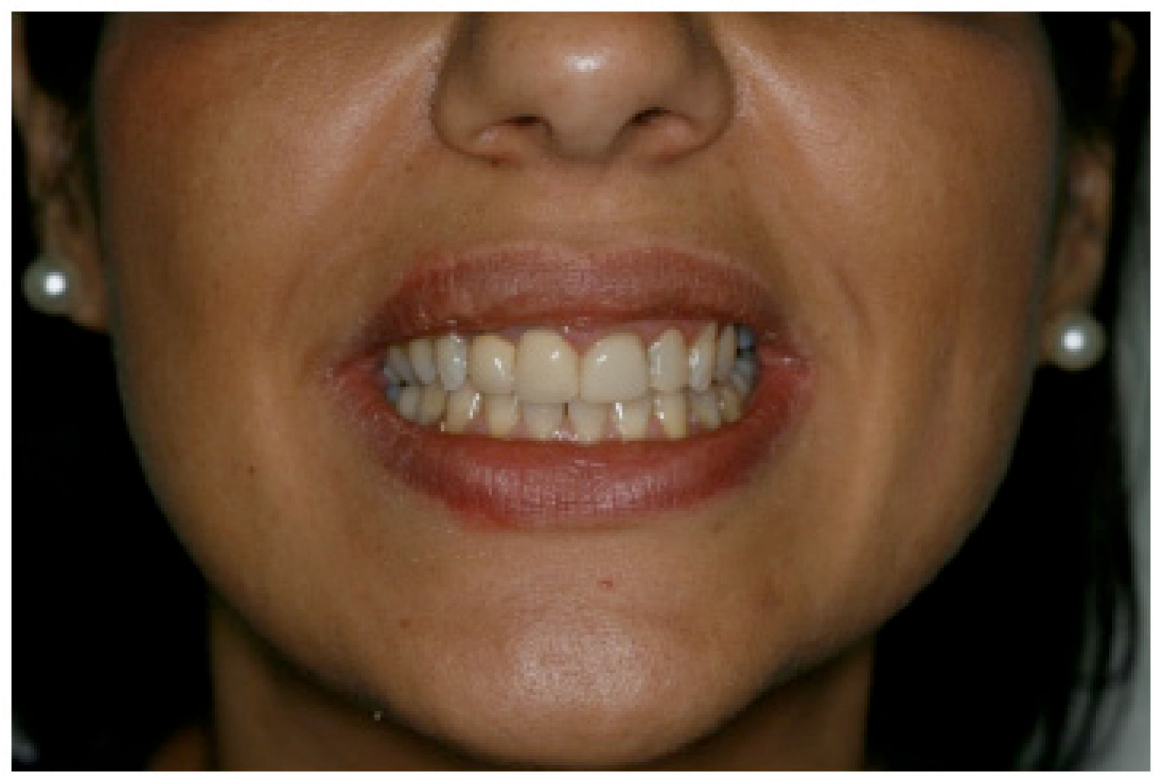

Fig. (1). Initial clinical condition.

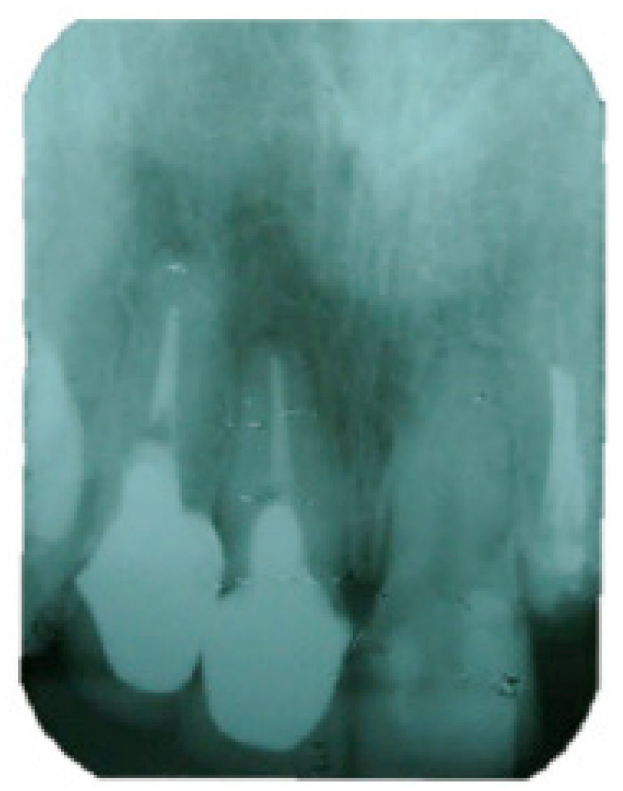

Fig. (2). Initial condition, as shown by radiography.

The first step was to apply the digital smile concept individually (Fig. 3) to evaluate the gingival level (A) and the tooth form and contour (B). For the determination of the contour, we used Microsoft ${ }^{\mathrm{TM}}$ Power Point 2010 (Microsoft Corp., Redmond, WA, USA). The tool used is found on the Insert tab, options Form - Line - Curve. This method allows the establishment of contours in irregular structures. At each click of the mouse, the tool inserts a vertex point along the path, allowing the monitoring of the general contours of the gums and also the format of the teeth. After this isolated evaluation, both analyses are put together (C), allowing the correct contour for each structure. The facial profile showed no discrepancy of midline, and the incisal edge was correct. In this way, the Golden Proportion was applied for 
the central incisors (the central incisor height is approximately $62 \%$ of the two central incisors' width), and the midline was confirmed by measuring the distance between the upper cuspids (D). In this planning phase, within the tab insert form - rectangle, use was made of a rectangle with the proportions set at 100-62. For this purpose, within the same software, there is the creation of a rectangle without shading. Clicking with the left-hand button of the mouse, on top of the rectangle, one can choose the options for size and also for position. On this screen, there is the option to adapt the proportions, so that the desired proportion may be reached. Once the central incisor width was determined, the Golden Proportion was applied again (E) to determine the lateral incisor width ( $62 \%$ of the central incisor width) and canine width ( $62 \%$ of the lateral incisor width). From the initial smile design, it could be noted that there was almost no horizontal discrepancy between the tooth, only a vertical irregularity (F). Measures and proportion were transferred to the stone cast allowing an appropriate wax-up (G). The wax-up was duplicated in acrylic resin and the mock-up was set in the patient. The patient used this provisional restoration for one week to seek approval by family and society. After this one-week period and with the patient's aesthetic approval, the gingivectomy was performed guided by the tooth contour of the provisional restoration $(\mathbf{H})$.

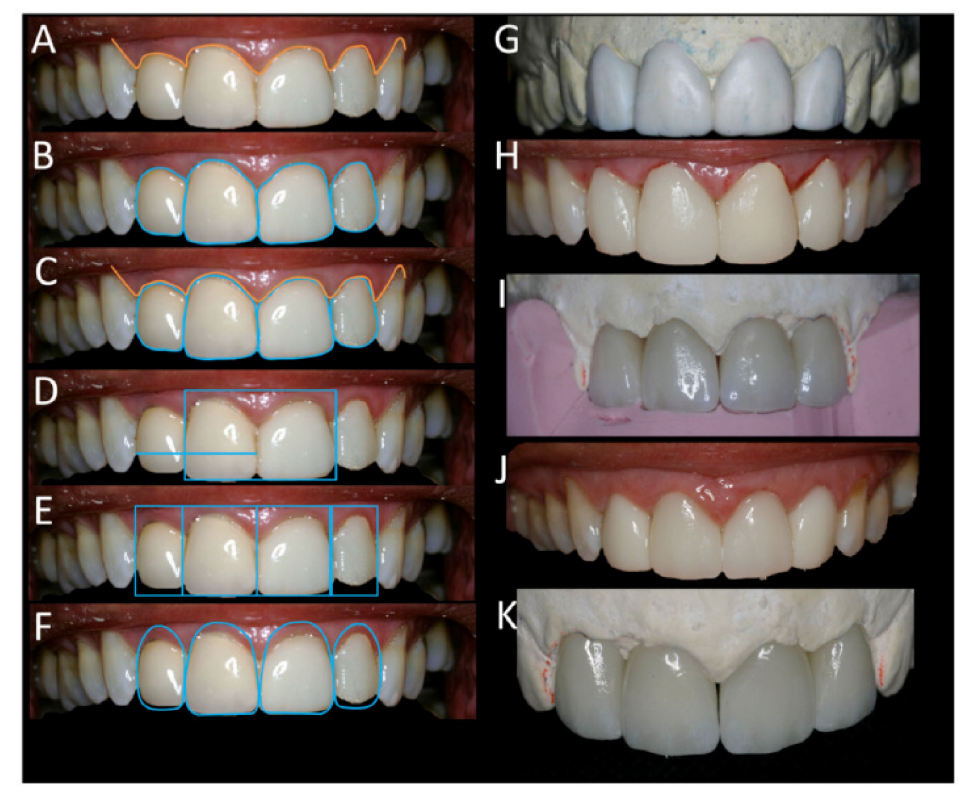

Fig. (3). Aesthetic planning and procedure phases: (A) gingival contour; (B) tooth contour; (C) tooth and gingival contour combined; (D) midline and central incisor height determination; (E) lateral incisor width determination; (F) design of the new tooth contour; (G) wax-up; (H) provisional restoration and gingivectomy; (I) crown design based on wax-up; (J) crown proof and adjustment (K) final aspect after staining.

The following steps were removing the core-crown and proceeding with the endodontic retreatment in both lateral incisors. Right central incisor presented a satisfactory endodontic treatment. Fibreglass posts were cemented in these teeth. The left central incisor presented satisfactory dental remains for a full-crown tooth preparation, thus avoiding the need for endodontic treatment.

The same silicon used in the diagnosis wax-up duplication was used to guide the crown wax-up (I), once the use of heat-pressed ceramic crown (Lithium Zirconate - Celmat Materiais Odontológicos, São Carlos, SP, Brazil) was determined. Crowns were set in the patient and the adjustment procedures were performed specially in protrusion $(\mathbf{J})$. Once the contour and form was correct, the staining procedures were performed with the correct colour and incisal characterization $(\mathbf{K})$.

The elective colour was B2 for the medium and cervical third. The incisal third was characterized with the blue shade mimicking the translucence of this area. White satin was applied on the incisal third improving the tooth characterization. Crowns were cemented with Relyx ARC A2 (3M ESPE St. Paul, MN, EUA) promoting a satisfactory final aesthetic result (Fig. 4). The 6 months control radiograph (Fig. 5) and photograph (Fig. 6) illustrate the periodontal and prosthetic stability. 


\section{DISCUSSION}

When it comes to the risk of root fracture, both metal and fibreglass posts seem to present similar results [7]. Despite this fact, the use of fibreglass posts becomes more frequent with the use of pressed porcelain because of its translucence. The use of $\mathrm{NiCr}$ core post may present some colour alterations and need to be covered by opaque resin cement to avoid colour change [3]. Translucent porcelain leads to a more natural appearance. Furthermore, tooth preparation can be more conservative once there is no necessity of a large amount of wear to accommodate the opaque porcelain layer. In this case the fibreglass post was indicated to avoid colour alteration due to the material's optical properties, which in turn is more aesthetically pleasing than other opaque materials [8].

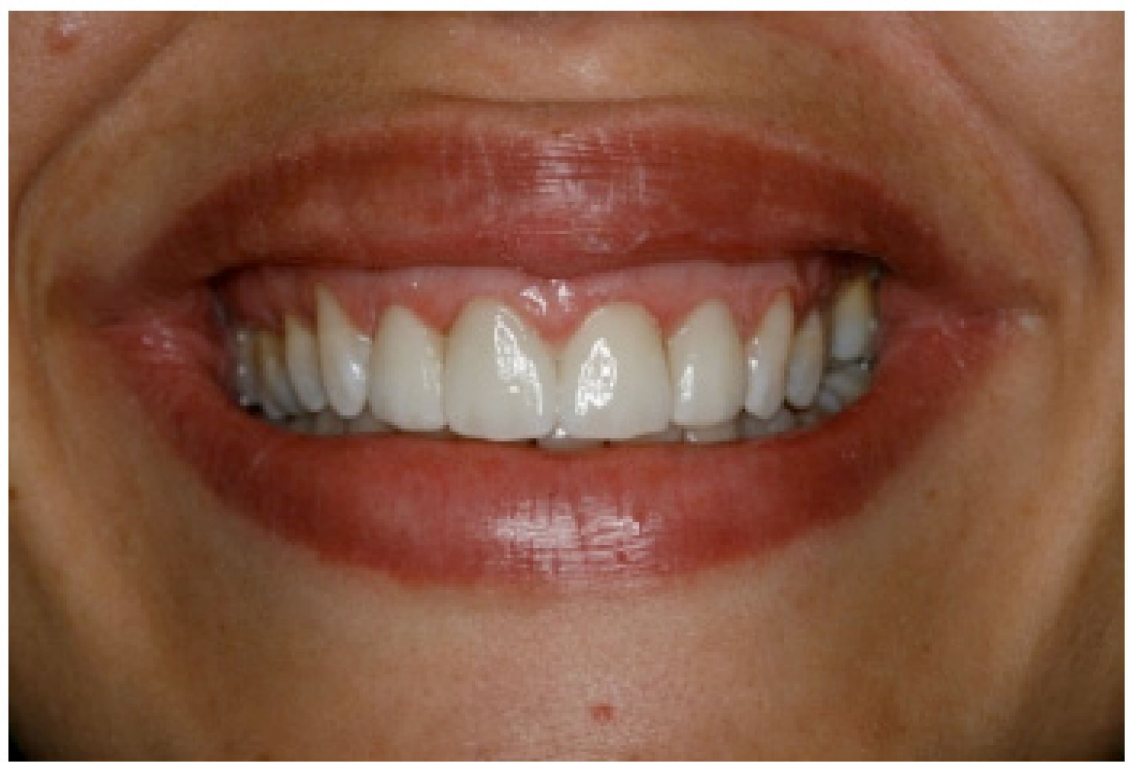

Fig. (4). Final aesthetic result.

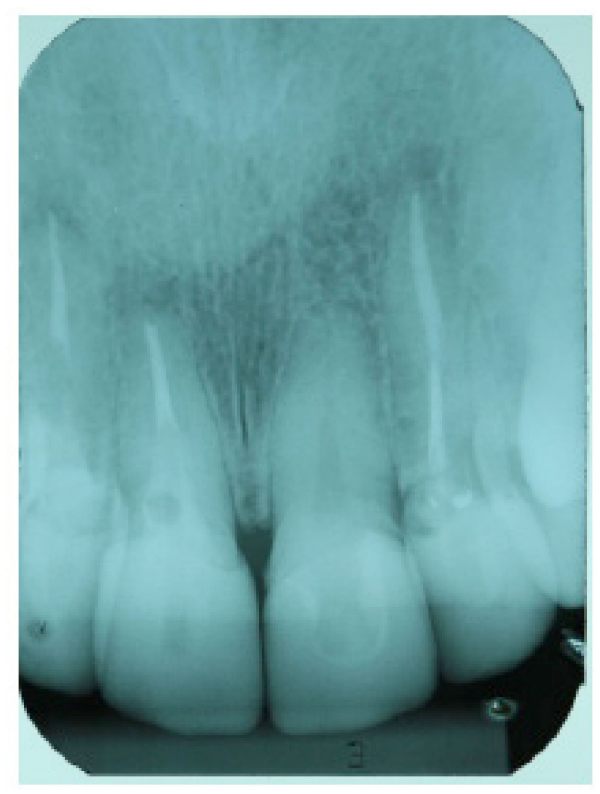

Fig. (5). Control radiograph (6 months).

Anterior tooth restoration normally poses a challenge to set the correct chroma. Several patient visits to the dental office may be necessary before a satisfactory result is achieved. Depending on the type of porcelain used, a new firing process may result in distortion. Even the pressed ceramic may suffer alterations due to repeated firing process on the pressing temperature which can range from $900^{\circ}$ to $950^{\circ}$ [9]. To avoid this issue pressed ceramic crown presents a low 
stain firing cycle temperature $\left(720^{\circ}-770^{\circ}\right)$. Both stain and glaze firing cycle do not jeopardize the crown marginal fit $[10,11]$.

Aesthetic restoration and full mouth veneer seem to have gained popularity. Even small tooth alteration is starting to be treated in this way, rather than through orthodontic treatment, due to the short treatment period. Unfortunately, this practice may lead to unnecessary treatment with loss of healthy dental structure [12].

In this case all necessary procedures have been performed within the ethical conduct. To achieve a satisfactory result it was established that the cuspids did not need to be restored with porcelain veneers, but the patient granted full agreement to undergo this procedure if it was necessary. Most important to her was to feel comfortable with her smile. The patient reported that her new smile changed according to other people's perception. A harmonic smile is an important factor for attractiveness and personality perception, especially with the opposite sex. A beautiful smile is often associated to a successful, intelligent and friendly person, and these concepts are associated to wealth [13]. All these factors support why aesthetic treatments have become so popular.

To proceed with a correct digital planning it is essential to follow a photographic protocol. The correct photograph position can provide important information to the aesthetic planning [14]. On the other hand, an incorrect photography may lead to a distorted picture which in turn may result in incorrect proportions. It is important to emphasize that any type of digital smile planning is only an assistance tool. After the planning, a provisional restoration test drive will provide the patient and the clinician with the final result preview. At this time, some artistic concepts must be applied individually for each patient to harmonize facial form with the dental composition [15]. Different proportions between the teeth $(62-80 \%)$ may be established as a guide for prosthetic rehabilitation. Each proportion needs to bear in mind the format of the arch and also the alignment of the teeth, as this proportion does not affect the width of the teeth, but does indeed affect the width they seem to have when seen from a frontal view [16]. In the case studied, the Patient showed an alignment according to a clear arch. In this way, the Golden Proportion proved to be more appropriate for solution of the case. This fact was confirmed by the position of the canine, being fully within the virtual plan made for the Golden Proportion.

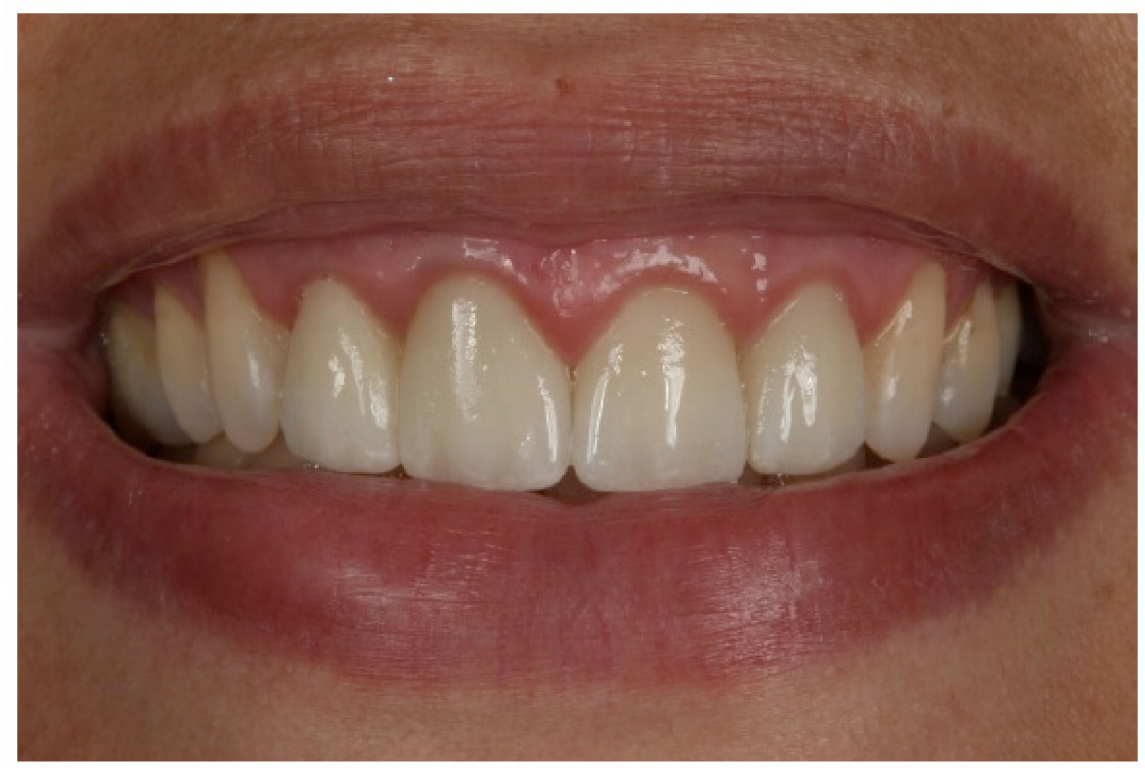

Fig. (6). Control photograph (6 months).

After all these evaluations and with the provisional restoration periodontal, surgical procedures may be necessary to provide a correct tooth form. In the present case, only a gingivectomy was necessary due to the small amount of gum resection and a favourable osseous crest position and biologic width. The patient presented a probing depth around $3 \mathrm{~mm}$ in the mid facial face. This higher probing depth could be caused by the anterior mismatched crown [17]. The biological width can range from 2.15 to 2.30 [18]; in this case no bone resection was necessary as the amount of gingival recontouring wouldn't invade the biological width. If the recontouring invades the biological width, a new relation between alveolar crest and restoration margin must be planned. The crest should be around $2.6 \mathrm{~mm}$ from the 
margin of the restoration to ensure a correct biological width [19]. When crown lengthening is required, the use of proportion gauges seems to optimize the planning and guide the surgery [20]. Success is beyond standard measures and ratios. A complete evaluation must be performed including intra and extra oral structures to achieve a natural result [21]. In addition, the opinions of the patient and of the people close to him or her are paramount to success

\section{CONCLUSION}

Not only is digital smile design an aesthetic guide protocol but its steps make the treatment phases more predictable for both patient and clinician, as the final design can be seen on the computer and be used by the patient during the provisional restoration steps. All-ceramic crown associated to fibreglass post may lead to a more natural tooth translucence that improves the aesthetic result.

\section{CONFLICT OF INTEREST}

The authors confirm that this article content has no conflict of interest.

\section{ACKNOWLEDGEMENTS}

Declared none.

\section{REFERENCES}

[1] Muts EJ, van Pelt H, Edelhoff D, Krejci I, Cune M. Tooth wear: a systematic review of treatment options. J Prosthet Dent 2014; 112(4): 752-9.

[http://dx.doi.org/10.1016/j.prosdent.2014.01.018] [PMID: 24721500]

[2] Coachman C, Calamita M. Digital smile design: A tool for treatment planning and communication in esthetic dentistry quintessence of dental technology. United States: Quintessence 2012; pp. 103-2.

[3] Ge J, Wang XZ, Feng HL. Influence of different post core materials on the color of Empress 2 full ceramic crowns. Chin Med J (Engl) 2006; 119(20): $1715-20$

[PMID: 17097019]

[4] Goyal MK, Goyal S, Hegde V, Balkrishana D, Narayana AI. Recreating an esthetically and functionally acceptable dentition: a multidisciplinary approach. Int J Periodontics Restorative Dent 2013; 33(4): 527-32.

[http://dx.doi.org/10.11607/prd.0381] [PMID: 23820713]

[5] Davarpanah M, Jansen CE, Vidjak FM, Etienne D, Kebir M, Martinez H. Restorative and periodontal considerations of short clinical crowns. Int J Periodontics Restorative Dent 1998; 18(5): 424-33. [PMID: 10093519]

[6] Ittipuriphat I, Leevailoj C. Anterior space management: interdisciplinary concepts. J Esthet Restor Dent 2013; 25(1): 16-30. [http://dx.doi.org/10.1111/j.1708-8240.2012.00515.x] [PMID: 23374405]

[7] Figueiredo FE, Martins-Filho PR. Faria-E-Silva AL. Do metal post-retained restorations result in more Root fractures than fiber post-retained restorations? A systematic review and meta-analysis. J Endod 2014; 41(3): 309-16. [PMID: 25459568]

[8] Spear F, Holloway J. Which all-ceramic system is optimal for anterior esthetics? J Am Dent Assoc 2008; 139(Suppl.): 19-24. [http://dx.doi.org/10.14219/jada.archive.2008.0358] [PMID: 18768905]

[9] Tang X, Tang C, Su H, Luo H, Nakamura T, Yatani H. The effects of repeated heat-pressing on the mechanical properties and microstructure of IPS e.max Press. J Mech Behav Biomed Mater 2014; 40: 390-6. [http://dx.doi.org/10.1016/j.jmbbm.2014.09.016] [PMID: 25300063]

[10] Cho SH, Nagy WW, Goodman JT, Solomon E, Koike M. The effect of multiple firings on the marginal integrity of pressable ceramic single crowns. J Prosthet Dent 2012; 107(1): 17-23. [http://dx.doi.org/10.1016/S0022-3913(12)60011-0] [PMID: 22230912]

[11] Balkaya MC, Cinar A, Pamuk S. Influence of firing cycles on the margin distortion of 3 all-ceramic crown systems. J Prosthet Dent 2005; 93(4): 346-55. [http://dx.doi.org/10.1016/j.prosdent.2005.02.003] [PMID: 15798685]

[12] Simonsen RJ. Commerce versus care: troubling trends in the ethics of esthetic dentistry. Dent Clin North Am 2007; 51(2): 281-7. [http://dx.doi.org/10.1016/j.cden.2007.03.002] [PMID: 17532912]

[13] Beall AE. Can a new smile make you look more intelligent and successful? Dent Clin North Am 2007; 51(2): 289-97. [http://dx.doi.org/10.1016/j.cden.2007.02.002] [PMID: 17532913]

[14] Goodlin R. Photographic-assisted diagnosis and treatment planning. Dent Clin North Am 2011; 55(2): 211-27. [http://dx.doi.org/10.1016/j.cden.2011.02.001] [PMID: 21473989] 
[15] Calamia JR, Levine JB, Lipp M, Cisneros G, Wolff MS. Smile design and treatment planning with the help of a comprehensive esthetic evaluation form. Dent Clin North Am 2011; 55(2): 187-209. [http://dx.doi.org/10.1016/j.cden.2011.01.012] [PMID: 21473988]

[16] Ward DH. Proportional smile design using the recurring esthetic dental (red) proportion. Dent Clin North Am 2001; 45(1): 143-54. [PMID: 11210692]

[17] Ganji KK, Patil VA, John J. A comparative evaluation for biologic width following surgical crown lengthening using gingivectomy and ostectomy procedure. Int J Dent 2012 2012; : 1-9. [http://dx.doi.org/10.1155/2012/479241]

[18] Schmidt JC, Sahrmann P, Weiger R, Schmidlin PR, Walter C. Biologic width dimensions-a systematic review. J Clin Periodontol 2013; 40(5): 493-504.

[http://dx.doi.org/10.1111/jcpe.12078] [PMID: 23461747]

[19] Herrero F, Scott JB, Maropis PS, Yukna RA. Clinical comparison of desired versus actual amount of surgical crown lengthening. J Periodontol 1995; 66(7): 568-71.

[http://dx.doi.org/10.1902/jop.1995.66.7.568] [PMID: 7562348]

[20] Chu SJ. A biometric approach to predictable treatment of clinical crown discrepancies. Pract Proced Aesthet Dent 2007; 19(7): 401-9. [PMID: 17929681]

[21] Davis NC. Smile design. Dent Clin North Am 2007; 51(2): 299-318. [http://dx.doi.org/10.1016/j.cden.2006.12.006] [PMID: 17532914]

Received: December 31, 2014

Revised: October 28, 2015

Accepted: November 15, 2015

(C) Zanardi et al. ; Licensee Bentham Open

This is an open access article licensed under the terms of the Creative Commons Attribution-Non-Commercial 4.0 International Public License (CC BY-NC 4.0) (https://creativecommons.org/licenses/by-nc/4.0/legalcode), which permits unrestricted, non-commercial use, distribution and reproduction in any medium, provided the work is properly cited. 